\title{
A Conserved Pattern of Differential Expansion of Cortical Areas in Simian Primates
}

\author{
Tristan A. Chaplin, ${ }^{1}$ Hsin-Hao Yu, ${ }^{1}$ Juliana G. M. Soares, ${ }^{3}$ Ricardo Gattass, ${ }^{3}$ and Marcello G. P. Rosa ${ }^{1,2}$ \\ ${ }^{1}$ Department of Physiology and ${ }^{2}$ Monash Vision Group, Monash University, Clayton, Victoria, 3800, Australia, and ${ }^{3}$ Programa de Neurobiologia, \\ Universidade Federal do Rio de Janeiro, Instituto de Biofísica Carlos Chagas Filho, Rio de Janeiro, Rio de Janeiro 21941-900, Brazil
}

The layout of areas in the cerebral cortex of different primates is quite similar, despite significant variations in brain size. However, it is clear that larger brains are not simply scaled up versions of smaller brains: some regions of the cortex are disproportionately large in larger species. It is currently debated whether these expanded areas arise through natural selection pressures for increased cognitive capacity or as a result of the application of a common developmental sequence on different scales. Here, we used computational methods to map and quantify the expansion of the cortex in simian primates of different sizes to investigate whether there is any common pattern of cortical expansion. Surface models of the marmoset, capuchin, and macaque monkey cortex were registered using the software package CARET and the spherical landmark vector difference algorithm. The registration was constrained by the location of identified homologous cortical areas. When comparing marmosets with both capuchins and macaques, we found a high degree of expansion in the temporal parietal junction, the ventrolateral prefrontal cortex, and the dorsal anterior cingulate cortex, all of which are high-level association areas typically involved in complex cognitive and behavioral functions. These expanded maps correlated well with previously published macaque to human registrations, suggesting that there is a general pattern of primate cortical scaling.

\section{Introduction}

Simian primates share a common plan of subdivision of the cerebral cortex into areas. This is evident in the relative position and cytoarchitecture of homologous areas in New and Old World monkeys (Paxinos et al., 2009, 2012), which diverged from a common ancestor $\sim 40$ million years ago (Fleagle, 1998; Chatterjee et al., 2009). However, this common plan has been modified in evolution with respect to various factors, including brain size. For example, the human brain has $\sim 180$ times the volume of that of the diminutive marmoset monkey (Stephan et al., 1981). Although a similar layout of homologous sensory, motor, and association areas can be recognized in both these species (Burman et al., 2011; Reser et al., 2013), it is also clear that some regions of the cerebral cortex have become disproportionately larger in the human brain (Deacon, 1990; Rilling and Insel, 1999; Semendeferi et al., 2001; Orban et al., 2004; Rosa and Tweedale, 2005; Rakic, 2009; Preuss, 2011; Kaas, 2013). Quantifying the way different areas scale with brain size could provide insight into the way the more complex cognitive abilities that differentiate humans from monkeys have developed in primate evolution.

Received July 3, 2013; revised Aug. 13, 2013; accepted Aug. 14, 2013.

Author contributions: M.G.P.R. designed research; T.A.C., H.-H.Y., J.G.M.S., and R.G. performed research; T.A.C., H.-H.Y., and M.G.P.R. analyzed data; T.A.C., H.-H.Y., and M.G.P.R. wrote the paper.

This work was supported by Australian Research Council Grant DP110101200. We thank David Van Essen for providing the macaque to human registration, Rowan Tweedale for many suggestions which improved the text, and Karyn Richardson and Sherry Zhao for plotting the sections.

The authors declare no competing financial interests.

Correspondence should be addressed to Marcello Rosa, Department of Physiology, Monash University, Clayton, Victoria, 3800, Australia. E-mail: marcello.rosa@monash.edu.

DOI:10.1523/JNEUROSCI.2909-13.2013

Copyright $\odot 2013$ the authors $\quad 0270-6474 / 13 / 3315120-06 \$ 15.00 / 0$
The principal drivers of non-uniform expansion of the brain remain a topic of debate (for review, see Striedter, 2005). One theory, known as mosaic evolution, proposes that evolutionary pressure to develop specific functions leads to the expansion of specific brain regions (Krubitzer and Seelke, 2012; Smaers and Soligo, 2013). An alternative explanation is concerted evolution, which proposes that the non-uniform scaling of neural structures derives primarily from the application of a common developmental program to species with different brain and body sizes. For example, according to one of the best-supported models, late-developing structures tend to become disproportionally large in larger species (Finlay and Darlington, 1995; Finlay et al., 2001), possibly because they tend to be the destinations of neurons that originate from cell divisions that occur toward the end of neurogenesis, either in late gestation or postnatally (Rakic, 2000; Finlay et al., 2001). One likely implication of the latter model is that the relative expansion ratios for different cortical areas would be conserved across comparisons involving simian primates of different sizes. In other words, the "hotspots" of expansion would tend to remain similar, regardless of which species are being compared.

Previous studies have compared the distribution and size of presumptive homologous areas in macaques and humans using surface-based methods (Orban et al., 2004; Van Essen and Dierker 2007; Hill et al., 2010). These studies found that high expansion ratios apply to high-order association areas, which mature relatively later in development, particularly compared with primary sensory and motor areas. In the present study, we used the surface registration method to investigate the scaling of the cortex in two species of New World primates, the marmoset (Callithrix jacchus) and capuchin (Cebus apella) monkeys, rela- 

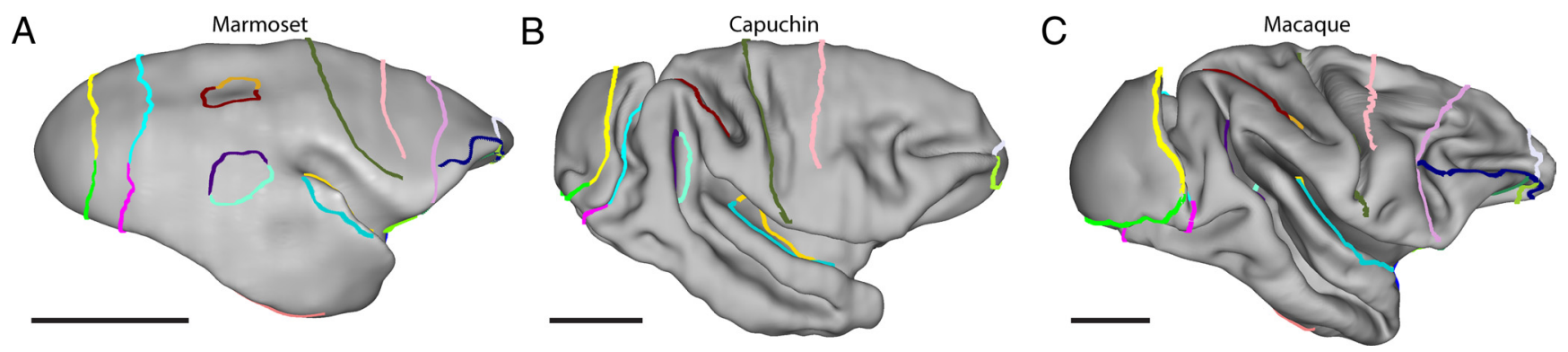

Figure 1. Lateral views of the cortical models of the three monkey species used in this study, from smallest to largest. Scale bars, $10 \mathrm{~mm}$. The models were warped to one another by anchoring to landmarks drawn as colored lines on the surface. $\boldsymbol{A}$, Marmoset (smallest model). B, Capuchin (medium-sized model). C, Macaque (largest model).

tive to macaques and humans, both of which are Old World simian primates with larger brains.

\section{Materials and Methods}

Because there are large differences in the folding pattern of the cortex across species, we used surface-based methods that inflate the cortex to a smooth representation (Van Essen, 2004) and map one brain to another by anchoring to a set of landmarks, represented by areas for which homology has been established (Van Essen et al., 2012a).

Surface-based three-dimensional models of marmoset and capuchin monkey cortex were reconstructed from coronal sections. The midthickness contour of the cortex was drawn and then serially reconstructed to create three-dimensional models using the software package CARET (Van Essen et al., 2001). The marmoset model was constructed from a published atlas (Paxinos et al., 2012) in which all cortical areas were identified. The capuchin model was created from an unpublished dataset, in which the sections were aligned manually and selected cortical areas were identified from cytoarchitecture and myeloarchitecture (Gallyas stain) by reference to previously published maps (Colombo et al., 1990; Rosa et al., 1993, 2000; Gattass et al., 2005; Padberg et al., 2007; Cruz-Rizzolo et al., 2011). The model was corrected for shrinkage based on photographs of the fixed intact brain but not for shrinkage during perfusion. The marmoset model was registered to both the capuchin model and to a published atlas of the rhesus macaque (the F99 atlas, Van Essen, 2004; Van Essen and Dierker, 2007; Van Essen et al., 2012a) using the landmark vector difference algorithm (Van Essen et al., 2012a) in CARET. The registration works by first inflating the models to spheres and then deforming one spherical model to match it to the other by aligning a set of landmarks (Fig. 1).

Fifteen landmarks were used in the marmoset to capuchin registration. Most of these landmarks corresponded to areas with clear architectural boundaries: the dorsal and ventral boundaries of the primary visual area (V1; Fig. 1, yellow and green lines), the rostral boundaries of the dorsal and ventral components of the second visual area (V2; cyan and magenta), the dorsal and ventral boundaries of the middle temporal area (MT; indigo and aquamarine), the caudal boundary of somatosensory area $3 \mathrm{~b}$ (dark olive green), the rostral boundary of motor area 4 (light pink), the medial and lateral boundaries of the auditory core areas (gold and dark turquoise), and the caudal border of area 10 in the dorsolateral prefrontal and orbitofrontal cortices (lavender and light green). In addition, we used two gross anatomical landmarks (the dorsal boundary of the midline cortex and the ventral boundary of the midline cortex). In the case of the marmoset to macaque registration, an additional seven landmarks were used, which were afforded by the comprehensive cytoarchitectural maps that are available for these species, based on a similar set of cytoarchitectural criteria (Paxinos et al., 2009, 2012). These included the boundary between the ventral and medial intraparietal areas, the lateral borders of medial temporal areas TL/TLO and TF/TFO, the rostral border of the area 8 complex (with areas 9,46D, and 46V), the combined border between frontal areas $12 \mathrm{~L}$ and 45 (ventrally) and $8 \mathrm{aV}$ and $46 \mathrm{~V}$ (dorsally), the combined lateral border of orbitofrontal areas $11 \mathrm{~L}$ and $13 \mathrm{~L}$ with subdivisions of area 12 , and the combined caudal border of the orbital paleocortex and proisocortex. The macaque to human registration was published previously by Orban et al. (2004), Van Essen and Dierker
(2007), and Hill et al. (2010), and the dataset was downloaded from http://sumsdb.wustl.edu/sums/download.do?archive_id=6595030

As a result of the registration processes, the model meshes were rebuilt so that each of the polygons in each model uniquely mapped to a single polygon in every other model. Expansion maps were then calculated by measuring the increase in the size of each mesh polygon between two registered species. This expansion ratio was then smoothed using the average of neighboring polygons for 100 iterations. To calculate the average primate expansion map, the maps were first normalized to be between 0 and 1 and then averaged at each polygon. The marmoset surface atlas and the interspecies registration are available for download from http://sumsdb.wustl.edu/sums/directory. do?id=8294741\&dir_name $=$ Expansion

\section{Results}

The surface area of the model of the marmoset cortex (a $500 \mathrm{~g}$ female) was $963 \mathrm{~mm}^{2}$, whereas that of the capuchin cortex (a 3.3 $\mathrm{kg}$ male) was $6796 \mathrm{~mm}^{2}$. The cortex of the capuchin resembles that of the macaque in terms of sulcal morphology (Le Gros Clark, 1959; Gattass et al., 2005), despite being noticeably smaller. The cortex of the macaque (Macaca mulatta; body mass of the studied individual not reported), the most gyrencephalic of the three monkey species studied, had a surface area nearly twice as large $\left(11,876 \mathrm{~mm}^{2}\right)$ as that of the capuchin. Quantifying the expansion of individual cortical areas can be problematic whenever these are not mapped in detail or subdivisions are not agreed on (Kaas, 2005; Rosa et al., 2013). However, given that we computationally registered one species to another, we could calculate expansion continuously across the entire surface by anchoring the graphic transformations to well defined, homologous regions.

The marmoset to macaque registration showed high degrees of expansion (up to $30 \times$ larger) in the temporal parietal junction, the ventrolateral prefrontal cortex, and the intraparietal sulcus (Fig. 2A). There was also moderately high expansion (up to $20 \times$ ) in the dorsal part of the anterior cingulate cortex. The occipital lobe, particularly V1, showed the lowest levels of expansion $(\sim 4-$ $6 \times)$, whereas the ventral part of the temporal lobe, the motor and somatosensory areas, and the orbital prefrontal cortex showed low to moderate levels of relative expansion $(4-8 \times)$.

A similar pattern was revealed by focusing on an intermediate scaling step (marmoset to capuchin registration), which also showed the highest degree of expansion in the temporal parietal junction, the ventrolateral prefrontal cortex, and the intraparietal sulcus (up to $16 \times$ larger) and considerable expansion in the anterior cingulate cortex $(10-12 \times$; Fig. $2 B)$. In addition, this registration revealed preferential expansion of the cortex encompassing the superior temporal gyrus and the caudal insula. The majority of the occipital lobe, ventral temporal cortex, motor and somatosensory cortices, and orbital prefrontal cortex had much lower levels of relative expansion. 

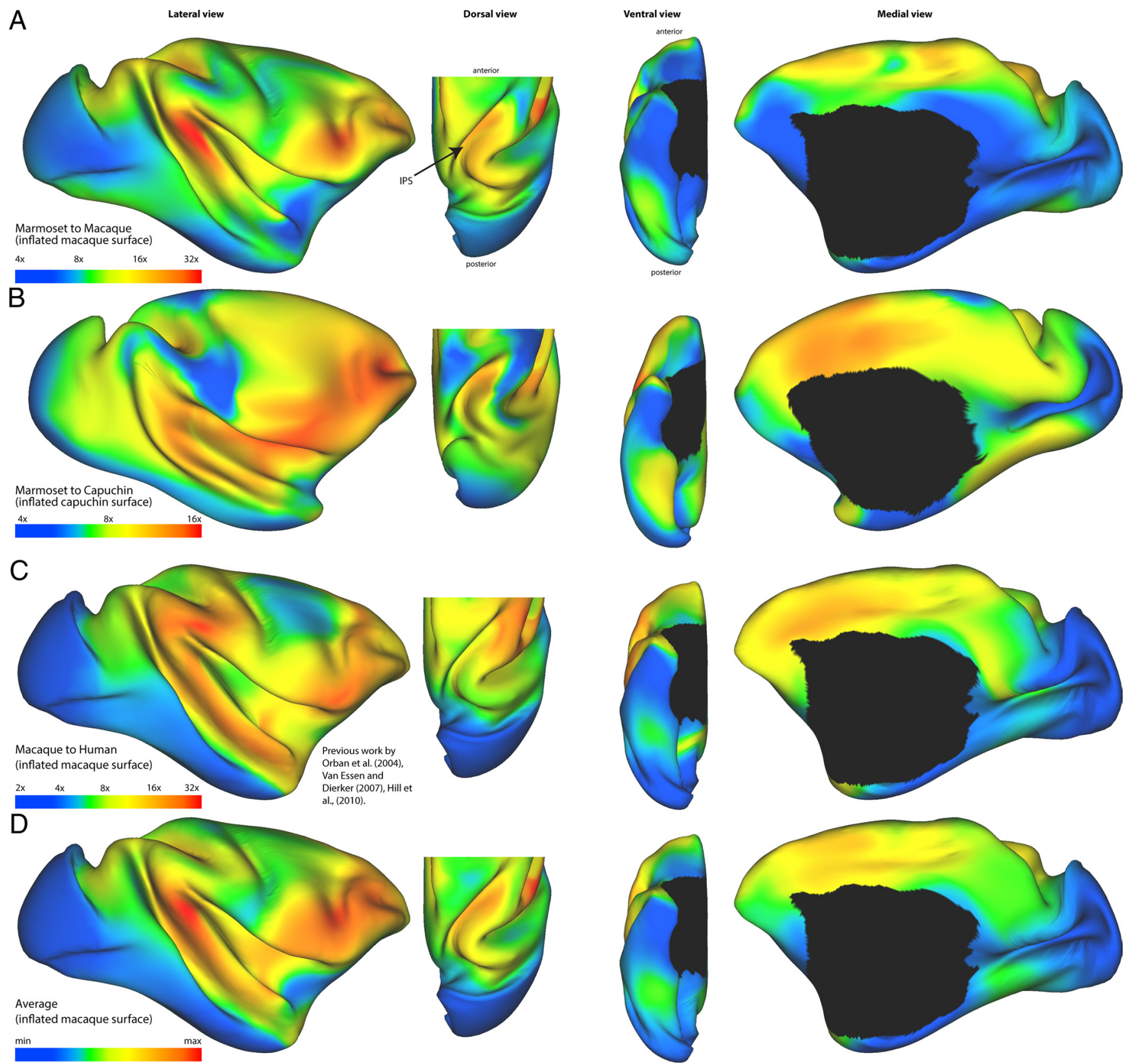

Figure 2. The pattern of expansion of the cortex with brain size is similar across species. After registering the models from Figure 1, expansion is visualized here by coloring inflated models of the cortex, with blue and green indicating regions that have relatively low levels of expansion compared with yellow and red areas with high levels of expansion (note log scale). Each panel shows four different viewpoints, from left to right: lateral, dorsal, ventral, and medial views. In the dorsal view, only the caudal part of the brain is shown to emphasize the parietal lobe. $A$, Marmoset to macaque expansion shown on the macaque model. B, Marmoset to capuchin expansion shown on the capuchin model. C, Macaque to human expansion shown on the macaque model from 0rban et al. (2004), Van Essen and Dierker (2007), and Hill et al. (2010). D, Average expansion between all three maps shown on the macaque model.

These results are similar to the macaque to human registration and expansion map (Fig. 2C; Orban et al., 2004; Hill et al., 2010), most notably with respect to significant expansion in the ventrolateral prefrontal cortex, anterior cingulate cortex, and temporal parietal junction. However, the macaque to human registration also showed evidence of expansion of parts of the inferior parietal lobule, unlike in the registrations between the marmoset and other species.

Averaging the expansion maps (Figs. 2D, 3) revealed a conserved pattern of expansion for the primate species in this study, in which the temporal parietal junction and ventrolateral prefrontal cortex appeared to be the most prominent centers of expansion. These hotspots were apparent in all species to species registrations, including from the marmoset to the human brain (Fig. 2A-C).

\section{Discussion}

One of the fundamental questions related to brain evolution can be stated as follows: do certain areas of the cortex grow disproportionally because they are key to cognitive capacities that are subject to strong natural selection, or is the pattern of brain expansion primarily driven by the application of a common developmental program? According to the latter interpretation, the greater cognitive capacities that can emerge as the brain scales up are primarily determined by the concentration of extra neural machinery in specific regions. Our results expand on previous 


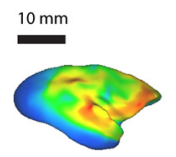

Marmoset

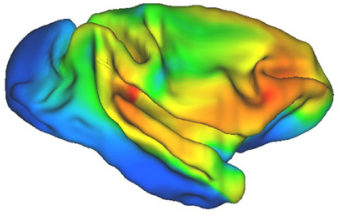

Capuchin

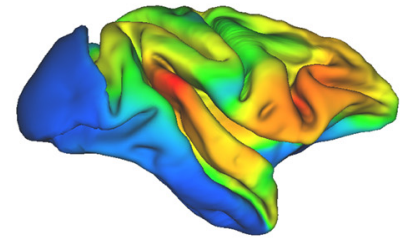

Macaque

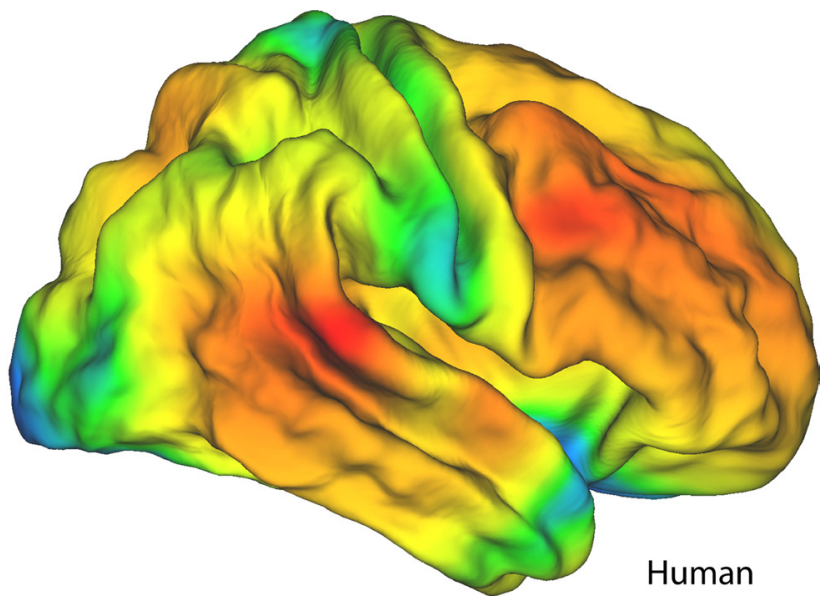

Figure 3. The average expansion map (from Fig. 2D) shown on cortical models of all four species, from the smallest species (marmoset) to the largest (human). The models are to scale and are colored by the average expansion map from Figure 2D. Note the expansion hotspots (red) in the temporal parietal junction and ventrolateral prefrontal cortex.
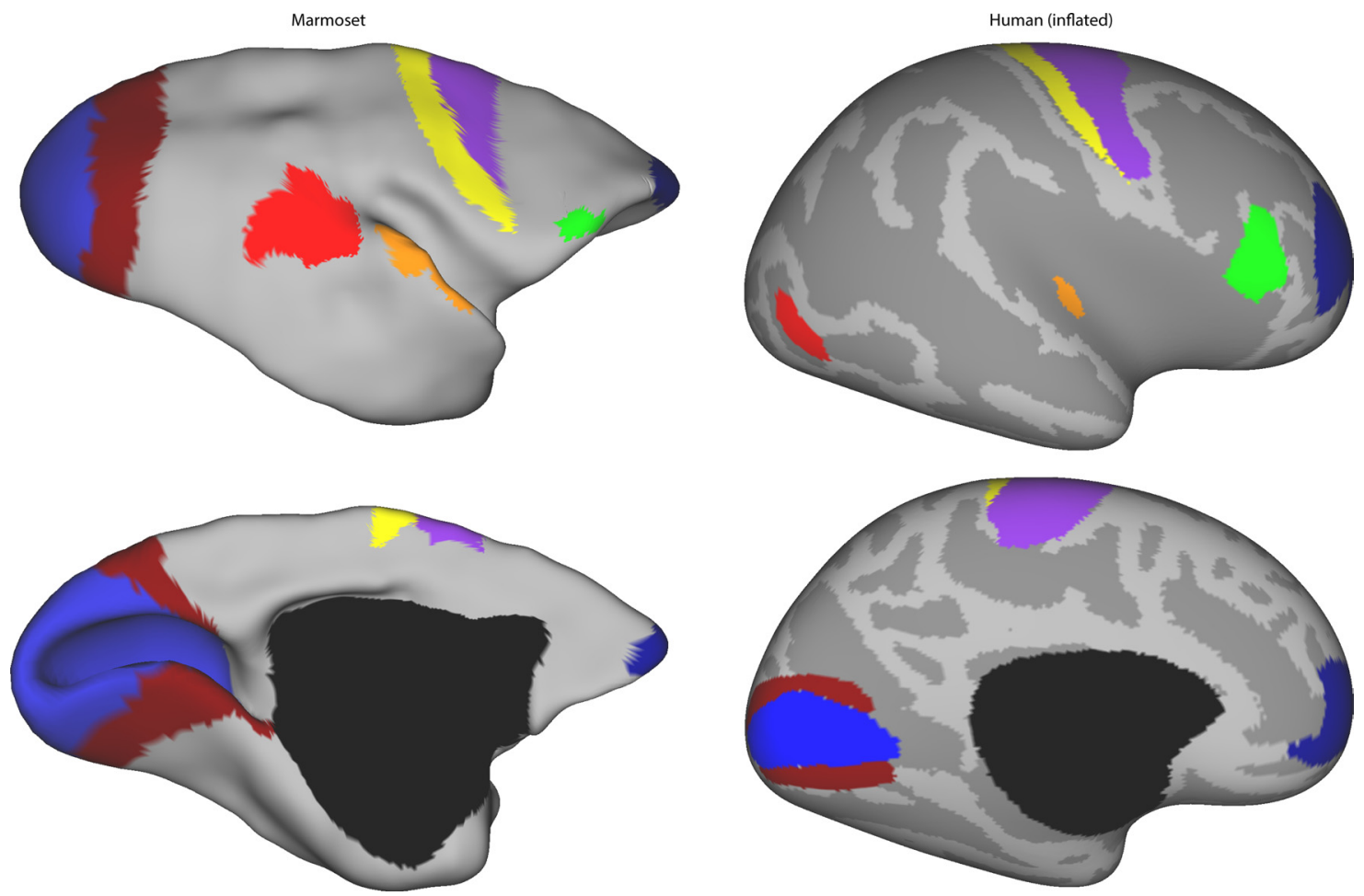

Figure 4. The non-uniform expansion of the primate cortex results in the shifting of the relative positions of cortical areas. A few of the homologous cortical areas are shown on the marmoset (left) and inflated human models (right): V1 (blue), V2 (maroon), MT/MST complex (MT+; red), auditory core (orange), primary somatosensory area (areas 3a and 3b; yellow), motor cortex (area 4, purple), area 45 (part of the frontal eye field; green), and area 10 (frontal pole; dark blue). The top row is the lateral view, and the bottom row is the medial view.

studies that have addressed the issue of non-uniform scaling of brains across species, by demonstrating the fundamental similarity of the primate brains of vastly different sizes. In other words, knowing how the cortex changes in a comparison involving the tiny marmoset and the capuchin or macaque can predict, to a great extent, the differences between the macaque and human cortices. However, it should be noted that the smaller species in this study are not ancestors of the larger species; rather, all species of living primates have evolved from extinct common ancestors. In fact, there is strong evidence to suggest that marmosets, as a group, have evolved from larger animals, through a process of "phyletic dwarfism" (Ford, 1980; Kelava et al., 2013; Montgomery and Mundy, 2013).
Our results support and expand the conclusions of Hill et al. (2010) by demonstrating that the evolution of the simian primate cortex was characterized by expansion centered on a few key hotspots (red areas in Figs. 2D, 3). The most striking feature of this expansion involves the temporal parietal junction. Between marmosets and humans, the increase in the size of this area is massive, as evidenced by the position of area MT changing from being almost adjacent to auditory cortex, to being widely separated (Fig. 4, red and orange areas). In humans, the cortex encompassed within this region of expansion has been implicated in high-level cognitive functions, such as speech (Edwards et al., 2010) and morality (Young et al., 2010), as well as the theory of mind (Saxe and Kanwisher, 2003). The second area of expansion 
is centered on the ventrolateral prefrontal cortex (Figs. 2D, 3). Again, this can be demonstrated by the relative separation of the primary motor cortex (area 4 ) and prefrontal area 45 in humans compared with marmosets (Fig. 4, purple and green regions, respectively). The ventrolateral prefrontal cortex is also associated with communication (Petrides and Pandya, 2009; Romanski, 2012), as well as other high-level functions, such as behavioral flexibility (particularly in a social context; Nelson and Guyer, 2011) and working memory (Wolf et al., 2006; Wilson et al., 2007). Furthermore, there is some expansion that encompasses the dorsal anterior cingulate cortex, a region of the cortex that has been associated with a wide variety of functions related to the appraisal and expression of emotion, reward processing, and problem solving (Devinsky et al., 1995; Allman et al., 2001; Etkin et al., 2011; Bissonette et al., 2013). Current estimates of the number of cortical areas in humans (150-200; Kaas, 2008; Van Essen et al., 2012b) are substantially higher than in the macaque or marmosets ( $\sim 140$ and $\sim 110$, respectively; Paxinos et al., 2012; Van Essen et al., 2012a). This reflects a more general trend toward an increase in the number of areas as a function of brain volume (Changizi and Shimojo, 2005). Although the evolutionary mechanisms that have led to the subdivision of the cortex into areas remain a subject of debate (for review, see Striedter, 2005), it is likely that the regions of preferential expansion that we have identified contributed significantly to this trend.

The identified areas of high expansion grow disproportionately during human postnatal development (Hill et al., 2010), in contrast with areas that mature early (such as the primary sensory cortices and MT; Bourne and Rosa, 2006). In principle, these observations reflect the "late equals large" principle (Finlay and Darlington, 1995; Striedter, 2005). As in the thalamus (Finlay et al., 2001), the longer maturation period could be a consequence of late rounds of cell division, which would allow a region to preferentially expand if it contains large proportions of lategenerated cells. However, it is unknown whether the developmental mechanisms that lead to differential expansion of areas are the same across species. In particular, this model relies on the assumption that the timetable of postnatal maturation of the cells in different cortical areas reflects that of their cell divisions, for which there is as yet no clear evidence. It has also been hypothesized that the regions of high expansion mature later in development to take advantage of postnatal experience (Weiner et al., 2008; Hill et al., 2010).

Superimposed on the fundamental similarity in the pattern of expansion, there are suggestions of some differences. For example, the differential expansion of the intraparietal areas is not as marked between marmosets and capuchins (or macaques) as that observed in the macaque to human registration. Conversely, the areas of the inferior parietal lobule show greater expansion in the comparison between the macaque and human brain. One possibility is that this simply reflects the imperfect knowledge about the layout of parietal areas, particularly in New World monkeys, in which the proposed borders are still primarily based on comparative architectonics and limited connectional data (Rosa et al., 2009; Paxinos et al., 2012). Consequently, more accurate reconstructions and registrations based on additional investigation of this region may reveal a more conserved pattern of parietal expansion. Here, it is important to recognize that our sample size only includes single individuals, from four species of simian primate. A better evaluation of the significance of the observed deviations from a strictly similar pattern of differential expansion of the cortex will undoubtedly require population-averaged maps of the cortex and, preferably, more species. Nonetheless, it has been acknowledged that some of the variation in the relationships between the volume of specific central nervous system structures (including cortical areas) and overall brain volume is likely to be attributable to other factors, which may include postnatal plasticity that is mediated by environmental interactions (Kaskan et al., 2005).

\section{Notes}

Supplemental material for this article is available at http://youtu. be/7wEjOfi9DiU. This movie is an animated version of Figure 3, showing the transformation of the cortex from the smallest species (marmoset) to the largest species (human). The models are to scale and are colored by the average expansion map. The animation shows the growth of the expansion hotspots (red) in the temporal parietal junction and ventrolateral prefrontal cortex, as well as the general pattern of change in the cortex as it scales up in size. This material has not been peer reviewed.

\section{References}

Allman JM, Hakeem A, Erwin JM, Nimchinsky E, Hof P (2001) The anterior cingulate cortex. The evolution of an interface between emotion and cognition. Ann N Y Acad Sci 935:107-117. CrossRef Medline

Bissonette GB, Powell EM, Roesch MR (2013) Neural structures underlying set-shifting: roles of medial prefrontal cortex and anterior cingulate cortex. Behav Brain Res 250:91-101. CrossRef Medline

Bourne JA, Rosa MGP (2006) Hierarchical development of the primate visual cortex, as revealed by neurofilament immunoreactivity: early maturation of the middle temporal area (MT). Cereb Cortex 16:405-414. CrossRef Medline

Burman KJ, Reser DH, Yu HH, Rosa MGP (2011) Cortical input to the frontal pole of the marmoset monkey. Cereb Cortex 21:1712-1737. CrossRef Medline

Changizi MA, Shimojo S (2005) Parcellation and area-area connectivity as a function of neocortex size. Brain Behav Evol 66:88-98. CrossRef Medline

Chatterjee HJ, Ho SY, Barnes I, Groves C (2009) Estimating the phylogeny and divergence times of primates using a supermatrix approach. BMC Evol Biol 9.

Colombo M, D’Amato MR, Rodman HR, Gross CG (1990) Auditory association cortex lesions impair auditory short-term memory in monkeys. Science 247:336-338. CrossRef Medline

Cruz-Rizzolo RJ, De Lima MA, Ervolino E, de Oliveira JA, Casatti CA (2011) Cyto-, myelo- and chemoarchitecture of the prefrontal cortex of the Cebus monkey. BMC Neurosci 12.

Deacon TW (1990) Problems of ontogeny and phylogeny in brain-size evolution. Int J Primatol 11:237-282. CrossRef

Devinsky O, Morrell MJ, Vogt BA (1995) Contributions of anterior cingulate cortex to behaviour. Brain 118:279-306. CrossRef Medline

Edwards E, Nagarajan SS, Dalal SS, Canolty RT, Kirsch HE, Barbaro NM, Knight RT (2010) Spatiotemporal imaging of cortical activation during verb generation and picture naming. Neuroimage 50:291-301. CrossRef Medline

Etkin A, Egner T, Kalisch R (2011) Emotional processing in anterior cingulate and medial prefrontal cortex. Trends Cogn Sci 15:85-93. CrossRef Medline

Finlay BL, Darlington RB (1995) Linked regularities in the development and evolution of mammalian brains. Science 268:1578-1584. CrossRef Medline

Finlay BL, Darlington RB, Nicastro N (2001) Developmental structure in brain evolution. Behav Brain Sci 24:263-278; discussion 278-308. CrossRef Medline

Fleagle JG (1998) Primate adaptation and evolution. San Diego: Academic. Ford SM (1980) Callitrichids as phyletic dwarfs, and the place of the Callitrichidae in Platyrrhini. Primates 21:31-34. CrossRef

Gattass R, Nascimento-Silva S, Soares JG, Lima B, Jansen AK, Diogo AC, Farias MF, Botelho MM, Mariani OS, Azzi J, Fiorani M (2005) Cortical visual areas in monkeys: location, topography, connections, columns, plasticity and cortical dynamics. Philos Trans R Soc Lond B Biol Sci 360: 709-731. CrossRef Medline

Hill J, Inder T, Neil J, Dierker D, Harwell J, Van Essen D (2010) Similar patterns of cortical expansion during human development and evolution. Proc Natl Acad Sci U S A 107:13135-13140. CrossRef Medline

Kaas JH (2005) The future of mapping sensory cortex in primates: three of 
many remaining issues. Philos Trans R Soc Lond B Biol Sci 360:653-664. CrossRef Medline

Kaas JH (2008) The evolution of the complex sensory and motor systems of the human brain. Brain Res Bull 75:384-390. CrossRef Medline

Kaas JH (2013) The evolution of brains from early mammals to humans. Wiley Interdiscip Rev Cogn Sci 4:33-45. CrossRef Medline

Kaskan PM, Franco EC, Yamada ES, Silveira LC, Darlington RB, Finlay BL (2005) Peripheral variability and central constancy in mammalian visual system evolution. Proc R Soc B 272:91-100. CrossRef Medline

Kelava I, Lewitus E, Huttner WB (2013) The secondary loss of gyrencephaly as an example of evolutionary phenotypical reversal. Front Neuroanat 7:16. CrossRef Medline

Krubitzer LA, Seelke AMH (2012) Cortical evolution in mammals: the bane and the beauty of phenotypic variability. Proc Natl Acad Sci U S A 109: 10647-10654. CrossRef Medline

Le Gros Clark LE (1959) The antecedents of man : an introduction to the evolution of the primates. Edinburgh: Edinburgh University Press.

Montgomery SH, Mundy NI (2013) Parallel episodes of phyletic dwarfism in callitrichid and cheirogaleid primates. J Evol Biol 26:810-819. CrossRef Medline

Nelson EE, Guyer AE (2011) The development of the ventral prefrontal cortex and social flexibility. Dev Cogn Neurosci 1:233-245. CrossRef Medline

Orban GA, Van Essen D, Vanduffel W (2004) Comparative mapping of higher visual areas in monkeys and humans. Trends Cogn Sci 8:315-324. CrossRef Medline

Padberg J, Franca JG, Cooke DF, Soares JG, Rosa MGP, Fiorani M Jr, Gattass R, Krubitzer L (2007) Parallel evolution of cortical areas involved in skilled hand use. J Neurosci 27:10106-10115. CrossRef Medline

Paxinos G, Huang XF, Petrides M, Toga AW (2009) The rhesus monkey brain in stereotaxic coordinates. San Diego: Academic.

Paxinos G, Watson C, Petrides M, Rosa MGP, Tokuno H (2012) The marmoset brain in stereotaxic coordinates. San Diego: Academic.

Petrides M, Pandya DN (2009) Distinct parietal and temporal pathways to the homologues of Broca's area in the monkey. PLoS Biol 7:e1000170. CrossRef Medline

Preuss TM (2011) The human brain: rewired and running hot. Ann N Y Acad Sci 1225:182-191. CrossRef Medline

Rakic P (2000) Radial unit hypothesis of neocortical expansion. Novartis Found Symp 228:30-42; discussion 42-52. Medline

Rakic P (2009) Evolution of the neocortex: a perspective from developmental biology. Nat Rev Neurosci 10:724-735. CrossRef Medline

Reser DH, Burman KJ, Yu HH, Chaplin TA, Richardson KE, Worthy KH, Rosa MGP (2013) Contrasting patterns of cortical input to architectural subdivisions of area 8: a retrograde tracing study in marmoset monkeys. Cereb Cortex 23:1901-1922. CrossRef Medline

Rilling JK, Insel TR (1999) The primate neocortex in comparative perspective using magnetic resonance imaging. J Hum Evol 37:191-223. CrossRef Medline

Romanski LM (2012) Integration of faces and vocalizations in ventral prefrontal cortex: implications for the evolution of audiovisual speech. Proc Natl Acad Sci U S A 109:10717-10724. CrossRef Medline

Rosa MGP, Tweedale R (2005) Brain maps, great and small: lessons from comparative studies of primate visual cortical organization. Philos Trans R Soc Lond B Biol Sci 360:665-691. CrossRef Medline

Rosa MGP, Soares JG, Fiorani M Jr, Gattass R (1993) Cortical afferents of visual area MT in the Cebus monkey: possible homologies between New and Old World monkeys. Vis Neurosci 10:827-855. CrossRef Medline

Rosa MGP, Piñon MC, Gattass R, Sousa AP (2000) Third tier ventral extrastriate cortex in the New World monkey, Cebus apella. Exp Brain Res 132:287-305. CrossRef Medline

Rosa MGP, Palmer SM, Gamberini M, Burman KJ, Yu HH, Reser DH, Bourne JA, Tweedale R, Galletti C (2009) Connections of the dorsomedial visual area: pathways for early integration of dorsal and ventral streams in extrastriate cortex. J Neurosci 29:4548-4563. CrossRef Medline

Rosa MGP, Angelucci A, Jeffs J, Pettigrew JD (2013) The case for a dorsomedial area in the primate "third-tier" visual cortex. Proc Biol Sci 280: 20121372; discussion 20121994. CrossRef Medline

Saxe R, Kanwisher N (2003) People thinking about thinking people. The role of the temporo-parietal junction in "theory of mind." Neuroimage 19:1835-1842. CrossRef

Semendeferi K, Armstrong E, Schleicher A, Zilles K, Van Hoesen GW (2001) Prefrontal cortex in humans and apes: a comparative study of area 10. Am J Phys Anthropol 114:224-241. CrossRef Medline

Smaers JB, Soligo C (2013) Brain reorganization, not relative brain size, primarily characterizes anthropoid brain evolution. Proc Biol Sci 280: 20130269. CrossRef Medline

Stephan H, Frahm H, Baron G (1981) New and revised data on volumes of brain structures in insectivores and primates. Folia Primatol (Basel) 35: 1-29. CrossRef Medline

Striedter GF (2005) Principles of brain evolution. Sunderland, MA: Sinauer Associates.

Van Essen DC (2004) Surface-based approaches to spatial localization and registration in primate cerebral cortex. Neuroimage 23:S97-S107. CrossRef Medline

Van Essen DC, Dierker DL (2007) Surface-based and probabilistic atlases of primate cerebral cortex. Neuron 56:209-225. CrossRef Medline

Van Essen DC, Drury HA, Dickson J, Harwell J, Hanlon D, Anderson CH (2001) An integrated software suite for surface-based analyses of cerebral cortex. J Am Med Inform Assoc 8:443-459. CrossRef Medline

Van Essen DC, Glasser MF, Dierker DL, Harwell J (2012a) Cortical parcellations of the macaque monkey analyzed on surface-based atlases. Cereb Cortex 22:2227-2240. CrossRef Medline

Van Essen DC, Glasser MF, Dierker DL, Harwell J, Coalson T (2012b) Parcellations and hemispheric asymmetries of human cerebral cortex analyzed on surface-based atlases. Cereb Cortex 22:2241-2262. CrossRef Medline

Weiner S, Monge J, Mann A (2008) Bipedalism and parturition: an evolutionary imperative for cesarean delivery? Clin Perinatol 35:469-478, ix. CrossRef Medline

Wilson CRE, Gaffan D, Mitchell AS, Baxter MG (2007) Neurotoxic lesions of ventrolateral prefrontal cortex impair object-in-place scene memory Eur J Neurosci 25:2514-2522. CrossRef

Wolf RC, Vasic N, Walter H (2006) Differential activation of ventrolateral prefrontal cortex during working memory retrieval. Neuropsychologia 44:2558-2563. CrossRef Medline

Young L, Camprodon JA, Hauser M, Pascual-Leone A, Saxe R (2010) Disruption of the right temporoparietal junction with transcranial magnetic stimulation reduces the role of beliefs in moral judgments. Proc Natl Acad Sci U S A 107:6753-6758. CrossRef Medline 